\title{
Hydroxychloroquine versus lopinavir/ritonavir in severe COVID-19 patients
}

\section{Results from a real-life patient cohort}

\author{
Mario Karolyi (D) - Erich Pawelka (D) - Theresa Mader · Sara Omid · Hasan Kelani · Sarah Ely · Bernd Jilma (D) \\ Sebastian Baumgartner · Hermann Laferl · Clemens Ott · Marianna Traugott · Michael Turner · Tamara Seitz • \\ Christoph Wenisch · Alexander Zoufaly
}

Received: 30 June 2020 / Accepted: 18 July 2020 / Published online: 10 August 2020

(C) Springer-Verlag GmbH Austria, part of Springer Nature 2020

\begin{abstract}
Summary
Background Severe acute respiratory syndrome coronavirus 2 (SARS-CoV-2) infection is associated with a high mortality. To date no trial comparing hydroxychloroquine (HCQ) and lopinavir/ritonavir (LPV/RTV) has been performed.

Methods Hospitalized patients $\geq 18$ years old with severe coronavirus disease 2019 (COVID-19) were treated with either HCQ or LPV/RTV if they had either respiratory insufficiency $\left(\mathrm{SpO}_{2} \leq 93 \%\right.$ on room air or the need for oxygen insufflation) or bilateral consolidations on chest X-ray and at least 2 comorbidities associated with poor COVID-19 prognosis. Outcomes investigated included in-hospital mortality, intensive care unit (ICU) admission, length of stay, PCR (polymerase chain reaction) negativity and side effects of treatment.

Results Of 156 patients (41\% female) with a median age of 72 years (IQR 55.25-81) admitted to our department, 67 patients fulfilled the inclusion criteria (20 received HCQ, 47 LPV/RTV). Groups were comparable regarding most baseline characteristics. Median time from symptom onset to treatment
\end{abstract}

The authors M. Karolyi and E. Pawelka contributed equally to the manuscript.

M. Karolyi (凶) $\cdot$ E. Pawelka $\cdot$ T. Mader $\cdot$ S. Omid $\cdot$ H. Kelani ·

S. Baumgartner $\cdot$ H. Laferl $\cdot$ C. Ott $\cdot$ M. Traugott $\cdot$ M. Turner .

T. Seitz $\cdot$ C. Wenisch $\cdot$ A. Zoufaly

Department for Infectious Diseases and Tropical Medicine, Kaiser-Franz-Josef Hospital, Kundratstraße 3, 1100 Vienna, Austria

mario.karolyi@gesundheitsverbund.at

S. Ely · B. Jilma

Department of Clinical Pharmacology, Medical University of Vienna, Vienna, Austria initiation was 8 days and was similar between the groups ( $p=0.727)$. There was no significant difference (HCQ vs. LPV/RTV) in hospital mortality (15\% vs. $8.5 \%, p=0.418)$, ICU admission rate (20\% vs. $12.8 \%$, $p=0.470$ ) and length of stay (9 days vs. 11 days, $p=0.340$ ). A PCR negativity from nasopharyngeal swabs was observed in approximately two thirds of patients in both groups. Side effects led to treatment discontinuation in $15 \%$ of patients in the LPV/RTV group.

Conclusion No statistically significant differences were observed in outcome parameters in patients treated with HCQ or LPV/RTV but patients in the LPV/RTV group showed a numerically lower hospital mortality rate. Additionally, in comparison to other studies we demonstrated a lower mortality in patients treated with LPV/RTV despite having similar patient groups, perhaps due to early initiation of treatment.

Keywords SARS-CoV-2 · Treatment · Outcome · Austria $\cdot$ Real world data

\section{Introduction}

As of 30 June 2020 the SARS-CoV-2 pandemic has caused over 10 million infections and over 500,000 deaths worldwide [1]. The clinical manifestation of COVID-19 ranges from mild respiratory symptoms to acute respiratory distress syndrome and death. Case fatality rates vary by countries and are strongly associated with age, comorbidities and disease severity [2-6].

Several potential treatment options showed in vitro efficacy or activity against coronaviruses, such as severe acute respiratory syndrome (SARS), Middle East respiratory syndrome (MERS) and severe acute respi- 
ratory syndrome coronavirus 2 (SARS-CoV-2) [7-10]. The LOTUS trial (Lopinavir Trial for Suppression of SARS-Cov-2 in China) was the first randomized controlled trial (RCT) published. It compared the human immunodeficiency virus (HIV) drug lopinavir/ ritonavir (LPV/RTV) vs. placebo in 199 patients but did not show any significant difference in the primary endpoint time to clinical improvement; however, patients treated with LPV/RTV had a shorter stay on the intensive care unit (ICU) and the mortality rate was lower in absolute numbers. This, however, did not reach statistical significance [11]. The malaria drug hydroxychloroquine (HCQ) is another possible treatment, which has been suggested by some studies [12-14], whilst others have demonstrated more conflicting results [15-17, 27, 28]. Although all studies so far have had some methodological limitations, HCQ and LPV/RTV may be promising drugs and large international studies are currently ongoing $[9,18]$.

While the results of these trials are eagerly awaited, off-label use of both drugs is widely practiced during the current SARS-CoV-2 pandemic, and the risk of possible adverse events needs to be weighed against potential benefits. This article describes the efficacy and safety of antiviral treatment with HCQ or LPV/RTV in a real-life cohort of patients with COVID19.

\section{Methods}

\section{Study design}

This ongoing cohort study was conducted at the Department for Infectious Diseases and Tropical Medicine at the Kaiser-Franz-Josef Hospital in Vienna, Austria. All hospitalized patients $\geq 18$ years old with molecular proven SARS-CoV-2 infections were eligible for the study. Polymerase chain reaction (PCR) tests for SARS-CoV-2 took place at our hospital laboratory institute or at other certified laboratories in Vienna.

Patients qualified for an antiviral off-label treatment with HCQ or LPV/RTV if they met the inclusion criteria, did not meet any exclusion criteria and agreed to off-label use. Inclusion criteria: need for hospitalization plus respiratory insufficiency $\left(\mathrm{SpO}_{2} \leq 93 \%\right.$ at room air or need for oxygen insufflation) or bilateral consolidations as demonstrated on chest X-ray and at least two comorbidities associated with poor COVID19 prognosis (e.g. age $>60$ years, diabetes and hypertension). Exclusion criteria were defined to ensure maximum safety for the patients: patients who did not fulfil the inclusion criteria, contraindications for and known allergies to both drugs, low life expectancy, palliative setting, inability to understand and/or agree to the off-label use.

The treating physician made the decision regarding which treatment to use based on the comorbidities, concomitant medication and potential drug-drug interactions, contraindications and availability of drugs.

The HCQ was administered with a loading dose of $400 \mathrm{mg}$ twice daily on the first day, followed by $200 \mathrm{mg}$ twice daily. Contraindications for HCQ were prolonged QT interval (defined as QTc $>440 \mathrm{~ms}$ ), known retinopathies, psoriasis and known glucose-6-phosphate dehydrogenase deficiency. The LPV/RTV dose of $400 \mathrm{mg} / 100 \mathrm{mg}$ was administered twice daily and had the following contraindications: known human immunodeficiency virus (HIV) infection, severe liver disease and essential background medication with potentially relevant interactions. All concomitant medications were checked for interactions via http:// www.covid19-druginteractions.org and adapted as necessary. Duration of treatment was 5-10 days depending on disease severity and clinical progression.

Patients not treated with any drug were not considered a suitable control group because of indication bias. These patients did not receive any SARS-CoV-2specific antiviral treatment because of advanced age, very limited life expectancy or only mild disease.

Outcomes investigated included in-hospital mortality and ICU admission as well as length of stay (LOS), viral clearance and side effects of treatment.

\section{Definition of variables}

The first day of any COVID-19 associated symptom was considered as disease onset. Fever was defined as a body temperature $\geq 38^{\circ} \mathrm{C}$ measured by the patient at home (using any kind of thermometer) or during medical contact (via ear thermometers). Respiratory insufficiency was defined as $\mathrm{SpO}_{2} \leq 93 \%$ at room air or the need for supplementary oxygen. Dehydration was defined as the need for intravenous fluids based on clinical appearance. Side effects were attributed to the study drug if they appeared after the drug was initiated. Elevated liver enzymes were considered clinically relevant if they reached $>3$ times the upper limit of normal.

\section{Statistical analysis and data collection}

Patient symptoms, medical history, laboratory parameters and complications were collected via a standardized form during hospital admission. Incomplete data were updated retrospectively from patient electronic health records whenever possible.

Data were double checked, entered in a MS Excel sheet (Microsoft, Redmond, WA, USA) and anonymized before statistical analysis. All analyses were made with SPSS 25 (IBM, Armonk, NY, USA) for Mac OS (Apple, Cupertino, CA, USA). Categorial variables were described by counts and percentages. For metric non-normally distributed variables the median (Md) and interquartile range (IQR) were used. Significance tests for categorial variables were made via cross tables and $\chi^{2}$-test or Fisher's exact test, where applica- 
ble. Mann-Whitney U-tests were calculated for metric non-normally distributed variables. A two-sided alpha $<0.05$ was considered statistically significant.

Data described here were collected from 1 March to 26 April 2020. After this period the drugs were only prescribed within a randomized, controlled study setting.

The cohort study and retrospective analysis was approved by the local ethics committee.

\section{Results}

\section{General patient characteristics - whole population}

In total 156 patients with a median age of 72 years (IQR 55.25-81 years) were admitted to our department of whom $64(41 \%)$ were female. The median time to hospitalization after symptom onset was 7 days (IQR 3-10 days). The three most common symptoms were weakness, cough and fever. Of the patients 66 $(42.3 \%)$ presented with respiratory insufficiency and $104(66.7 \%)$ had consolidations on chest X-ray on admission. Hypertension was the most common underlying disease and present in $49.4 \%$ of patients, followed by atrial fibrillation (21.2\%), diabetes (19.2\%), chronic kidney disease (17.9\%) and chronic obstructive pulmonary disease $(14.7 \%)$.

Of the patients 67 received antiviral treatment; 20 HCQ monotherapy and 47 LPV/RPV monotherapy.
An ICU admission was necessary in $6.4 \%$ of patients and in-hospital mortality was $25 \%$. Median ICU stay was 5 days (IQR 2-7.5 days). Median length of stay of the survivors was 10 days (IQR 6.5-16 days). Follow-up swabs were performed in 104 patients, 53 (51\%) were PCR negative at the time of discharge with a median time from symptom onset to PCR negativity of 17 days (IQR 12.75-22.25 days). For details see Tables 1 and 2 and 4.

\section{Subgroup-no treatment}

Patients in this group had a median age of 77 years (IQR $60-85$ years) and 48.3\% were female. Time from symptom onset to hospitalization was 6 days (IQR 2-11 days). The in-hospital mortality rate was $36 \%$ with a median time from hospitalization to death of 8 days (IQR 5-11 days). No patients were transferred to the ICU. The LOS of the survivors in this group was 10 days (IQR 5.5-17 days). For details see Tables 1 and 2 and 4 .

Due to indication bias this group was not considered as a placebo or control group.

\section{$H C Q$ vs. $L P V / R P V$}

Patient characteristics and treatment

Patients who received monotherapy with either HCQ or LPV/RTV were compared.

Table 1 Patient demographics and medical history

\begin{tabular}{|c|c|c|c|c|c|}
\hline & $\begin{array}{l}\text { Total } \\
(N=156)\end{array}$ & $\begin{array}{l}\text { No treatment } \\
(n=89)\end{array}$ & $\begin{array}{l}\text { Hydroxychloroquine } \\
(n=20)\end{array}$ & Lopinavir/ritonavir ( $n=47)$ & $\begin{array}{l}p \text {-value }{ }^{c} \\
\text { HCQ vs. LPV/RTV }\end{array}$ \\
\hline Age $^{\mathrm{a}}$ (years) & $\begin{array}{l}72 \\
(55.25-81)\end{array}$ & $\begin{array}{l}77 \\
(60-85)\end{array}$ & $\begin{array}{l}62.5 \\
(46.5-78)\end{array}$ & $\begin{array}{l}65 \\
(49-72)\end{array}$ & 0.716 \\
\hline Sex (female) & $64(41 \%)$ & $43(48.3 \%)$ & $6(30 \%)$ & $15(31.9 \%)$ & 0.877 \\
\hline BMI $[107]^{a, b}$ & $\begin{array}{l}25.9 \\
(23.8-30.1)\end{array}$ & $\begin{array}{l}25.2 \\
(22.9-28.1)\end{array}$ & $\begin{array}{l}28.4 \\
(25.5-32.6)\end{array}$ & $\begin{array}{l}27.2 \\
(23.7-31.17)\end{array}$ & 0.202 \\
\hline \multicolumn{6}{|l|}{ Medical history } \\
\hline Hypertension & $77(49.4 \%)$ & $44(49.4 \%)$ & $14(70 \%)$ & $19(40.4 \%)$ & 0.034 \\
\hline $\begin{array}{l}\text { Smoker/former smoker } \\
{[129]^{b}}\end{array}$ & $44(34.1 \%)$ & $22(31.9 \%)$ & $5(27.8 \%)$ & $17(40.5 \%)$ & 0.396 \\
\hline Atrial fibrillation & $33(21.2 \%)$ & $23(25.8 \%)$ & $2(10 \%)$ & $8(17 \%)$ & 0.711 \\
\hline Diabetes & $30(19.2 \%)$ & $18(20.2 \%)$ & $3(15 \%)$ & $9(19 \%)$ & 1.0 \\
\hline Chronic kidney disease & $28(17.9 \%)$ & $20(22.5 \%)$ & $3(15 \%)$ & $5(10.6 \%)$ & 0.687 \\
\hline Coronary heart disease & $25(16 \%)$ & $17(19.1 \%)$ & $5(25 \%)$ & $3(6.4 \%)$ & 0.046 \\
\hline $\begin{array}{l}\text { Obstructive pulmonary dis- } \\
\text { ease }\end{array}$ & $23(14.7 \%)$ & $13(14.6 \%)$ & $4(20 \%)$ & $6(12.8 \%)$ & 0.470 \\
\hline Congestive heart failure & $19(12.2 \%)$ & $16(18 \%)$ & 0 & $3(6.4 \%)$ & 0.549 \\
\hline Any malignancy & $18(11.5 \%)$ & $16(18 \%)$ & 0 & $2(4.3 \%)$ & 1.0 \\
\hline Dementia & $16(10.3 \%)$ & $13(14.6 \%)$ & 0 & $3(6.4 \%)$ & 0.549 \\
\hline Rheumatic disease & $6(3.8 \%)$ & $2(2.2 \%)$ & $1(5 \%)$ & $3(6.4 \%)$ & 1.0 \\
\hline Peripheral artery disease & $11(7.1 \%)$ & $10(11.2 \%)$ & $1(5 \%)$ & 0 & 0.299 \\
\hline Hypothyroidism & $13(8.3 \%)$ & $6(6.7 \%)$ & $3(15 \%)$ & $4(8.5 \%)$ & 0.418 \\
\hline
\end{tabular}


Table 2 Symptoms and signs of patients on admission

\begin{tabular}{llllll} 
& $\begin{array}{l}\text { Total } \\
(N=156)\end{array}$ & $\begin{array}{l}\text { No treatment } \\
(n=89)\end{array}$ & $\begin{array}{l}\text { Hydroxychloroquine } \\
(n=20)\end{array}$ & Lopinavir/ritonavir $(n=47)$ & $\begin{array}{l}p \text {-value } \\
\text { HCQ vs. LPV/RTV }\end{array}$ \\
\hline $\begin{array}{l}\text { Time from symptom onset to hospi- } \\
\text { talization }\end{array}$ & 7 days & $\begin{array}{l}6 \text { days } \\
(3-10)\end{array}$ & $\begin{array}{l}7 \text { days } \\
(2-11)\end{array}$ & $\begin{array}{l}7 \text { days } \\
(4.25-10)\end{array}$ & 0.463 \\
\hline Weakness & $108(69.2 \%)$ & $59(66.3 \%)$ & $14(70 \%)$ & $35(74.5 \%)$ & 0.767 \\
\hline Cough & $95(60.9 \%)$ & $45(50.6 \%)$ & $17(85 \%)$ & $33(70.2 \%)$ & 0.238 \\
\hline Fever & $94(60.3 \%)$ & $50(56.2 \%)$ & $15(75 \%)$ & $29(61.7 \%)$ & 0.402 \\
\hline Dyspnea & $54(34.6 \%)$ & $28(31.5 \%)$ & $11(55 \%)$ & $15(31.9 \%)$ & 0.102 \\
\hline Dehydration & $56(35.9 \%)$ & $40(44.9 \%)$ & $4(20 \%)$ & $12(25.5 \%)$ & 0.760 \\
\hline Diarrhea & $26(16.7 \%)$ & $18(20.2 \%)$ & $3(15 \%)$ & $5(10.6 \%)$ & 0.687 \\
\hline Altered mental state & $32(20.5 \%)$ & $22(24.7 \%)$ & $2(10 \%)$ & $8(17 \%)$ & 0.711 \\
\hline Throat pain & $21(13.5 \%)$ & $10(11.2 \%)$ & $5(25 \%)$ & $(12.8 \%)$ & 0.282 \\
\hline Blocked nose & $10(6.4 \%)$ & $3(3.4 \%)$ & $3(15 \%)$ & $4(8.5 \%)$ & 0.418 \\
\hline Muscle/joint pain & $5(3.2 \%)$ & $3(3.4 \%)$ & 0 & $2(4.3 \%)$ & 1.0 \\
\hline Loss of smell/taste & $7(4.5 \%)$ & $5(5.6 \%)$ & $2(10 \%)$ & 0 & 0.086 \\
\hline Vomiting & $4(2.6 \%)$ & $1(1.1 \%)$ & 0 & $3(6.4 \%)$ & 0.549 \\
\hline Respiratory insufficiency & $66(42.3 \%)$ & $36(40.4 \%)$ & $10(50 \%)$ & $20(42.3 \%)$ & 0.602 \\
\hline Consolidation on chest X-ray & $104(66.7 \%)$ & $52(58.4 \%)$ & $13(65 \%)$ & $39(83 \%)$ & 0.121 \\
\hline $\begin{array}{l}\text { aMedian and interquartile range are shown } \\
\text { HCQ hydroxychloroquine, LPV/RTVlopinavir/ritonavir }\end{array}$ & & & & \\
\hline
\end{tabular}

Both groups did not differ in baseline characteristics, such as age, sex and most variables from the medical history. A significantly higher number of patients in the HCQ group suffered from hypertension (70\% vs. $40.4 \%, p=0.034$ ) and coronary heart disease ( $25 \%$ vs. $6.4 \%, p=0.046$ ). For details see Table 1 .

Median time from symptom onset to hospitalization ( 7 days vs. 7 days, $p=0.463$ ) and antiviral treatment initiation ( 8 days vs. 8 days, $p=0.727$ ) are identical in both groups. Median antiviral treatment duration did not significantly differ between groups (6 days vs. 7 days, $p=0.667$ ). Concomitant antibiotic treatment was administered in approximately one third of patients in each group (Tables 2 and 3).

\section{Outcome parameters}

There was no statistically significant difference in the primary endpoints between the two groups. In-hospital mortality was $15 \%$ in the HCQ group vs. $8.5 \%$ in the LPV/RTV group $(p=0.418)$. The ICU admission rates were not statistically different between groups (20\% HCQ vs. $12.8 \%$ LPV/RTV, $p=0.470$ ).

The LOS was 9 days (IQR 8-12 days) in the HCQ group vs. 11 days (IQR 6-12 days) in the LPV/RTV group $(p=0.340)$. Follow-up swabs were not performed for every patient. Out of 12 patients in the HCQ group 7 (58.3\%) were PCR negative in the nasopharyngeal swabs at the time of discharge with a median time of 15 days (IQR 9-17 days) after symptom onset. Out of 31 in the LPV/RTV group 20 (64.5\%) were PCR negative in nasopharyngeal swabs after a median of 17 days (IQR 13.5-22 days) after symptom onset. For details see Table 4.

\section{Safety and side effects}

In the HCQ group 1 patient complained of nausea, compared to $25.2 \%$ in the LPV/RTV group, 7 patients (14.9\%) in the LPV/RTV group developed diarrhea and $6(15.4 \%)$ patients stopped treatment due to side effects. The large pill size was the reason why one of the patients stopped treatment. Clinically relevant liver

Table 3 Treatment and side effects

\begin{tabular}{|l|l|l|l|}
\hline Antiviral treatment & Hydroxychloroquine $(n=20)$ & Lopinavir/ritonavir $(n=47)$ & $p$-value \\
\hline Time from symptom onset to antiviral treatment ${ }^{\mathrm{a}}$ & 8 days $(5-10)$ & 8 days $(5.25-10)$ & 0.727 \\
\hline Duration of antiviral treatment & 6 days $(5-8)$ & 7 days (3-8) & 0.667 \\
\hline Antibiotic treatment & $6(30 \%)$ & $18(38.3 \%)$ & 0.587 \\
\hline Side effects & & & 0.170 \\
\hline Stopped treatment due to side effects & 0 & $6(15.4 \%)$ & 0.088 \\
\hline Nausea & $1(5 \%)$ & $12(25.2 \%)$ & 0.094 \\
\hline Diarrhea & 0 & $7(14.9 \%)$ & 0.714 \\
\hline Elevated liver enzymes & $2(10 \%)$ & $7(14.9 \%)$ & \\
\hline aMedian and interquartile range are shown & & & \\
\hline
\end{tabular}


Table 4 Outcome

\begin{tabular}{|c|c|c|c|c|c|}
\hline Outcome & $\begin{array}{l}\text { Total } \\
(N=156)\end{array}$ & $\begin{array}{l}\text { No treatment } \\
(n=89)\end{array}$ & $\begin{array}{l}\text { Hydroxychloroquine } \\
(n=20)\end{array}$ & $\begin{array}{l}\text { Lopinavir/ritonavir } \\
(n=47)\end{array}$ & $\begin{array}{l}p \text {-value } \\
\text { HCQ vs. LPV/RTV }\end{array}$ \\
\hline In-hospital mortality & $39(25 \%)$ & $32(36 \%)$ & $3(15 \%)$ & $4(8.5 \%)$ & 0.418 \\
\hline Deceased after $X$ days in hospital ${ }^{\mathrm{a}}$ & $\begin{array}{l}7 \text { days } \\
(5-11.25)\end{array}$ & $\begin{array}{l}8 \text { days } \\
(5-11)\end{array}$ & 8 days (na) & 5.5 days $(4.25-10.5)$ & 0.858 \\
\hline ICU admission & $10(6.4 \%)$ & 0 & $4(20 \%)$ & $6(12.8 \%)$ & 0.470 \\
\hline $\begin{array}{l}\text { ICU admission after } X \text { days in } \\
\text { hospital }^{\mathrm{a}}\end{array}$ & $\begin{array}{l}3.5 \text { days } \\
(2-4.25)\end{array}$ & $\mathrm{Na}$ & $2(0.5-6.5)$ & $4(3-4.25)$ & 0.193 \\
\hline ICU duration & $\begin{array}{l}5 \text { days } \\
(2-7.5)\end{array}$ & $\mathrm{Na}$ & $6(3-6.75)$ & $3.5(2-12)$ & 0.741 \\
\hline Mechanical ventilation & $4(2.6 \%)$ & - & $2(10 \%)$ & $2(4.3 \%)$ & 0.577 \\
\hline Length of stay of survivors ${ }^{a}$ & $\begin{array}{l}10 \text { days } \\
(6.5-16)\end{array}$ & $\begin{array}{l}10 \text { days } \\
(5.5-17)\end{array}$ & 9 days (8-12) & 11 days $(6-16)$ & 0.340 \\
\hline $\begin{array}{l}\text { Nasopharyngeal swab PCR nega- } \\
\text { tive }[104]^{b}\end{array}$ & $53 / 104(51 \%)$ & $\begin{array}{l}26 / 61 \\
(42.6 \%)\end{array}$ & $7 / 12(58.3 \%)$ & $20 / 31(64.5 \%)$ & 0.737 \\
\hline Days until PCR negativitya & $\begin{array}{l}17 \text { days } \\
(12.75-22.25)\end{array}$ & $\begin{array}{l}17.5 \text { days } \\
(12.75-26.75)\end{array}$ & $\begin{array}{l}15 \text { days } \\
(9-17)\end{array}$ & $\begin{array}{l}17 \text { days } \\
(13.5-22)\end{array}$ & 0.234 \\
\hline
\end{tabular}

enzyme elevation was observed in 7 patients in the LPV/RTV group. No other side effects were observed. For details see Table 3.

\section{Discussion}

Among patients with severe COVID-19 who received antiviral treatment in our cohort, we found no significant difference in mortality between HCQ and LPV/RTV. Numerically less people in the LPV/RTV group died ( $8.5 \%$ vs. $15 \%)$. The high overall mortality rate of $25 \%$ highlights the severity of COVID-19 in our study population.

In the LOTUS trial a mortality rate of $19 \%$ of patients who were treated with LPV/RTV was observed. The median age was 58 years and treatment was initiated 13 days after symptom onset [11]. Patients treated with LPV/RTV in our study had a mortality rate of $8.5 \%$. They were generally older, with a median age of 65 years, had more comorbidities and treatment was started earlier (8 days after symptom onset). The early initiation of treatment might explain the lower mortality rate of patients treated with LPV/RTV in our study. This theory can be supported by the numerically lower mortality of patients treated within 12 days of disease onset in the LOTUS trial [11]. Furthermore, early treatment initiation was associated with better outcome in other viral infections such as SARS and influenza [19-23].

Data on efficacy and mortality in patients with severe COVID-19 treated with HCQ are only derived from observational studies. Possible efficacy is described in some small studies with mild to moderate disease with surrogate parameters [12-16]. A study performed in the USA (published as a non-peer reviewed preprint) analyzed data from 368 male veterans treated with HCQ with or without azithromycin compared to patients without treatment. Mortality rates were significantly higher in the HCQ $(27.8 \%)$ and HCQ plus azithromycin group (22.1\%) compared to the no treatment group (11.4\%). Time from symptom onset to treatment, criteria for treatment initiation, duration and dosage of treatment were not described [17]. Recently, two large observational studies each with approximately 1400 patients were conducted. One did not show any effect of HCQ treatment on the composite endpoint of intubation or death in hospitalized COVID-19 patients [27]. The other did not show any association of treatment with HCQ, azithromycin or both compared to neither treatment and in-hospital mortality in COVID-19 patients [28]. The in-hospital mortality in that study was $19.9 \%$ for patients treated only with HCQ and $25.7 \%$ for patients treated with HCQ and azithromycin [28]. Unfortunately, in both studies the time from symptom onset to treatment was not reported, neither were patients of subgroups compared who received early vs. late treatment $[27,28]$. Therefore, real conclusions about HCQ treatment efficacy cannot be drawn from these studies. In comparison the patients who received HCQ in our study were older and showed a mortality rate of $15 \%$.

Of the patients from whom nasopharyngeal followup swabs had been taken for PCR analysis, approximately two thirds were PCR negative at the time of discharge in both groups, with a median duration of 15 and 17 days (HCQ vs. LPV/RTV) after symptom onset. Time to PCR negativity was longer in our HCQ treated population compared to other trials where PCR negativity was observed in $60-100 \%$ of patient after 6-7 days of treatment [12, 15]. This might be due to disease severity. Our patients were older, had more comorbidities and more severe disease. 
Prolonged viral shedding was observed in patients with severe disease. In one study the median duration of viral shedding was 20 days in survivors, while deceased patients were unable to clear the virus [3]. Other studies showed similar results [24] or even longer viral shedding in survivors [25]. The triple combination of LPV/RTV, ribavirin and interferon beta 1-b might be another treatment option to reduce viral shedding. Patients with mild disease treated with this combination early in the disease course (with a median of 5 days after symptom onset) showed a significantly shorter time to PCR negativity of nasopharyngeal swabs compared to LPV/RTV treated patients (7 days vs. 12 days, $p=0.001$ ) [29].

In the LOTUS trial $40 \%$ of patient swabs were still RNA-PCR positive on day 28 [11]. It is unclear if such patients are still infectious. A study showed that viral cultures were negative 8 days after symptom onset but PCR was still positive. This suggests that patients beyond day 8 after onset of symptoms may be not infectious anymore despite viral RNA persistence on the mucous membrane of the nasopharynx [26]. Another study incubated Vero cell lines with 90 PCR SARSCoV-2 positive samples. No viral growth was observed 8 days after symptom onset or a cycle threshold of $>24$ [30]. These studies suggest that despite PCR positivity of nasopharyngeal samples infectivity is unlikely.

In our study the ICU admission rate was similar between treatment groups. There was no difference in LOS of survivors between HCQ and LPV/RTV in our study and LOS was comparable to the LOTUS trial. Patients in our study were only treated for 7 days with LPV/RTV compared to 14 days in the LOTUS trial [11]. This suggests that a shorter duration treatment may be sufficient if initiated early.

Side effects were mild to moderate and observed more frequently in the LPV/RTV group, leading to treatment discontinuation in $15 \%$ of the patients vs. $0 \%$ in the HCQ group. No severe side effects occurred in either of our study groups, suggesting that safe use is possible if a protocol designed by specialists is followed and off-label treatment can be justified with respect to the high mortality of severe COVID-19.

While more than 100 clinical trials are currently attempting to find the optimal treatment for COVID-19, no comparative study of HCQ and LPV/RTV has been performed to date [9]. The strength of our study is that we compared the efficiency of these drugs for the first time in patients with severe COVID-19. We focused on essential endpoints, such as mortality and ICU admission rate and not just on surrogate parameters.

Our study has some limitations. The small sample size limits interpretation. It is a retrospective single center observational cohort study that lacks both randomization and a placebo group. We had a subgroup of patients who were not treated with any drugs but it was not considered to be a placebo group because of potential indication bias. Patients in this subgroup did not receive treatment because they were considered either to be of advanced age with a limited life expectancy (as shown by the high mortality rate of $36 \%$ and no ICU admissions), were considered to have mild disease and did therefore not fulfil the inclusion criteria or did not or could not agree to off-label use.

Evidence for COVID-19 treatment options is growing continuously. The antiviral drug remdesivir showed clinical benefits in a large RCT with approximately 1000 patients. Compared to placebo patients treated with remdesivir had a significantly shorter time to clinical recovery (11 days vs. 15 days, $p<0.001$ ) and the effect was mostly driven by patients who received non-invasive ventilation. At day 14 there was a non-significant trend towards a reduced mortality $(7.1 \%$ vs. $11.9 \%$, hazard ratio for death 0.70 , 95\% CI 0.47-1.04), mostly driven by patients who required oxygen [31]. Another study showed that 5 days of treatment was equivalent to a 10-day course in most patients treated with remdesivir, except in patients who require mechanical ventilation, where a prolonged treatment may be beneficial [32].

Very recently data from more than 6500 patients enrolled in the RECOVERY trial showed a significant mortality reduction at day 28 in patients treated with $6 \mathrm{mg}$ dexamethasone for up to 10 days. Dexamethasone reduced in-hospital mortality in patients who required mechanical ventilation from $40.7 \%$ to $29 \%$ $(p<0.001)$ and in patents who required oxygen from $25 \%$ to $21.5 \%(p=0.002)$, but did not show any benefit in patients who did not require oxygen supplementation [33].

In summary, we were able to show that HCQ and LPV/RTV are safe treatment options with no statistically significant differences observed in outcome parameters. Patients treated with LPV/RTV had a numerically lower in-hospital mortality rate compared to patients treated with HCQ. Early treatment initiation may be crucial to improve patient outcome, which might explain the lower mortality rate in our LPV/RTV subgroup compared to that in the LOTUS trial.

Despite the promising results of remdesivir and dexamethasone neither drug showed positive effects in patients not requiring oxygen [31-33]. The use of LPV/RTV may serve as a treatment option in this population or in patients with contraindications for those drugs. Higher doses of LPV/RTV might be necessary to inhibit SARS-CoV-2 replication more efficiently [34].

The use of HCQ did not show any positive effects in two large observational trials $[27,28]$ but as long as results from RCTs are not available final conclusions about its efficacy cannot be drawn. Finally, we suggest that LPV/RTV might be used to treat COVID-19 if the patients meet certain criteria and can be enrolled in controlled clinical trials.

Conflict of interest M. Karolyi, E. Pawelka, T. Mader, S. Omid, H. Kelani, S. Ely, B. Jilma, S. Baumgartner, H. Laferl, C. Ott, 
M. Traugott, M. Turner, T. Seitz, C. Wenisch, and A. Zoufaly declare that they have no competing interests.

\section{References}

1. ECDC. COVID-19 situation update worldwide, as of 22 July 2020.2020 . https://www.ecdc.europa.eu/en/ geographical-distribution-2019-ncov-cases. Accessed: 30 June 2019.

2. Wu C, Chen X, Cai Y, et al. Risk factors associated with acute respiratory distress syndrome and death in patients with coronavirus disease 2019 pneumonia in Wuhan, China. JAMA Intern Med. 2020; https://doi.org/10.1001/ jamainternmed.2020.0994.

3. Zhou F, Yu T, Du R, et al. Clinical course and risk factors for mortality of adult inpatients with COVID-19 in Wuhan, China: a retrospective cohort study. Lancet. 2020; https:// doi.org/10.1016/S0140-6736(20)30566-3.

4. Guan WJ, Ni ZY, Hu Y, et al. China medical treatment expert group for Covid-19. Clinical characteristics of Coronavirus disease 2019 in China. N Engl J Med. 2020; https:// doi.org/ 10.1056/NEJMoa2002032.

5. Wu Z, McGoogan JM. Characteristics of and important lessons from the coronavirus disease 2019 (COVID-19) outbreak in China summary of a report of 72314 cases from the Chinese center for disease control and prevention. JAMA. 2020; https://doi.org/10.1001/jama.2020.2648.

6. Guan W-J, Liang W-H, Zhao Y, et al. Comorbidity and its impact on 1590 patients with Covid-19 in China: a nationwide analysis. Eur Respir J. 2020; https://doi.org/10. 1183/13993003.00547-2020.

7. Liu J, Cao R, Xu M, et al. Hydroxychloroquine, a less toxic derivative of chloroquine, is effective in inhibiting SARSCoV-2 infection in vitro. Cell Discov. 2020;6:16.

8. Yao X, Ye F, Zhang M, et al. In vitro antiviral activity and projection of optimized dosing design of hydroxychloroquine for the treatment of severe acute respiratory syndrome coronavirus 2 (SARS-coV-2). Clin Infect Dis. 2020; https:// doi.org/10.1093/cid/ciaa237.

9. Sanders J, Monogue ML, Jodlowski TZ, et al. Pharmacologic treatments for coronavirus disease 2019 (COVID-19). A review. JAMA. 2020; https://doi.org/10.1001/jama.2020. 6019.

10. Bhimraj A, Morgan RL, Shumaker AH, et al. Infectious diseases society of America Guidelines on the treatment and management of patients with COVID-19. IDSA guideline version 1.0.3. 2020. www.idsociety.org/ COVID19guidelines. Accessed: 5 May 2019.

11. Cao B, Wang Y, Wen D, et al. A trial of Lopinavir-ritonavir in adults hospitalized with severe Covid-19. N Engl J Med. 2020; https://doi.org/10.1056/NEJMoa2001282.

12. Gautret P, Lagier JC, Parola P, et al. Hydroxychloroquine and azithromycin as a treatment of COVID-19: results of an open-label non-randomized clinical trial. Int J Antimicrob Agents. 2020; https://doi.org/10.1016/j.ijantimicag.2020. 105949.

13. Gautret P, Lagier JC, Parola P, et al. Clinical and microbiological effect of a combination of hydroxychloroquine and azithromycin in 80 COVID-19 patients with at leasta six-day follow up: an observational study. Travel Med Infect Dis. 2020; https://doi.org/10.1016/j.tmaid.2020.101663.

14. Chen Z, Hu J, Zhang Z, et al. Efficacy of hydroxychloroquine in patients with COVID-19: results of a randomized clinical trial. medRxiv. 2020; https://doi.org/10.1101/2020.03.22. 20040758.

15. ChenJ,LiuD, LiuL, etal. A pilotstudyofhydroxychloroquine in treatment of patients with common coronavirus disease-
19 (COVID-19). J Zhejiang Univ (Med Sci). 2020; https:// doi.org/10.3785/j.issn.1008-9292.2020.03.03.

16. TangW, CaoZ, Han M, etal. Hydroxychloroquinein patients with COVID-19: an open-label, randomized, controlled trial. medRxiv. 2020; https://doi.org/10.1101/2020.04.10. 20060558.

17. Magagnoli J, Narendran S, Pereira F, et al. Outcomes of hydroxychloroquine usage in United States veterans hospitalized with Covid-19. medRxiv. 2020; https://doi. org/10.1101/2020.04.16.20065920.

18. WHO. "Solidarity" clinical trial for COVID-19 treatments. 2020. https://www.who.int/emergencies/ diseases/novel-coronavirus-2019/global-research-onnovel-coronavirus-2019-ncov/solidarity-clinical-trialfor-covid-19-treatments. Accessed: 5 May2019.

19. Yao TT, Qian JD, Zhu WY, et al. A systematic review of lopinavir therapy for SARS coronavirus and MERS coronavirus-A possible reference for coronavirus disease-19 treatment option. J Med Virol. 2020; https://doi.org/10. 1002/jmv.25729.

20. Chan KS, Lai ST, Chu CM, et al. Treatment of severe acute respiratory syndrome with lopinavir/ritonavir: a multicentre retrospective matched cohort study. Hong Kong Med J. 2003;9((6):399-406.

21. Katzen J, Kohn R, Houk J, et al. Early oseltamivir after hospital admission is associated with shortened hospitalization: a five-year analysis of oseltamivir timing and clinical outcomes. Clin Infect Dis. 2019;69(1):52-8. https:// doi.org/10. 1093/ cid/ciy860.

22. European Centre for Disease Prevention and Control. Expert opinion on neuraminidase inhibitors for the prevention and treatment of influenza-Review of recent systematic reviews and meta-analyses. Stockholm: ECDC; 2017. https://doi.org/10.2900/01723.

23. Uyeki TM, Bernstein HH, Bradley JS, et al. Clinical practice guidelines by the infectious diseases society of america: 2018 update on diagnosis, treatment, chemoprophylaxis, and institutional outbreak management of seasonal influenza. Clin Infect Dis. 2019;68(6):e1-47.

24. XuK, Chen Y, Yuan J, etal. Factors associated with prolonged viral RNA shedding in patients with COVID-19. Clin Infect Dis. 2020; https://doi.org/10.1093/cid/ciaa351.

25. Zhou B, She J, WangY, etal. The duration of viral shedding of discharged patients with severe COVID-19. Clin Infect Dis. 2020; https://doi.org/10.1093/cid/ciaa451.

26. Wölfel R, Corman VM, Guggemos W, et al. Virological assessment of hospitalized patients with COVID-2019. Nature. 2020; https://doi.org/10.1038/s41586-020-2196-x.

27. Geleris J, Sun Y, PlattJ, et al. Observational study of hydroxychloroquine in hospitalized patients with Covid-19. NEng J Med. 2020; https://doi.org/10.1056/NEJMoa2012410.

28. RosenbergE, DufortE, Udo T, et al. Association of treatment with hydroxychloroquine or azithromycin with in-hospital mortality in patients with COVID-19 in New York state. JAMA. 2020; https://doi.org/10.1001/jama.2020.8630.

29. Hung IF, Lung KC, Tso EY, et al. Triple combination of interferon beta-1b, lopinavir-ritonavir, and ribavirin in the treatment of patients admitted to hospital with COVID-19: an open-label, randomised, phase 2 trial. Lancet. 2020;395(10238):1695-704. https://doi.org/10. 1016/S0140-6736(20)31042-4.

30. Bullard J, Dust K, Funk D, et al. Predicting infectious SARSCoV-2 from diagnostic samples. Clin Infect Dis. 2020; https://doi.org/10.1093/cid/ciaa638.

31. Beigel JH, Tomashek KM, Dodd LE, et al. Remdesivir for the treatment of Covid-19-Preliminary Report. N Engl J Med. 2020; https://doi.org/10.1056/NEJMoa2007764. 
32. Goldman JD, Lye DCB, Hui DS, et al. Remdesivir for 5 or 10 days in patients with severe Covid-19. n Engl J Med. 2020; https://doi.org/10.1056/NEJMoa2015301.

33. Horby P, Lim WS, Emberson J, et al. Effect of dexamethasone in hospitalized patients with COVID-19: preliminary report. medRxiv. 2020; https://doi.org/10.1101/2020.06. 22.20137273 .
34. Schörgenhofer C, Jilma B, Stimpfl T, et al. Pharmacokinetics of lopinavir and ritonavir in patients hospitalized with coronavirus disease 2019 (COVID-19). Ann Intern Med. 2020; https://doi.org/10.7326/M20-1550.

Publisher's Note Springer Nature remains neutral with regard to jurisdictional claims in published maps and institutional affiliations. 